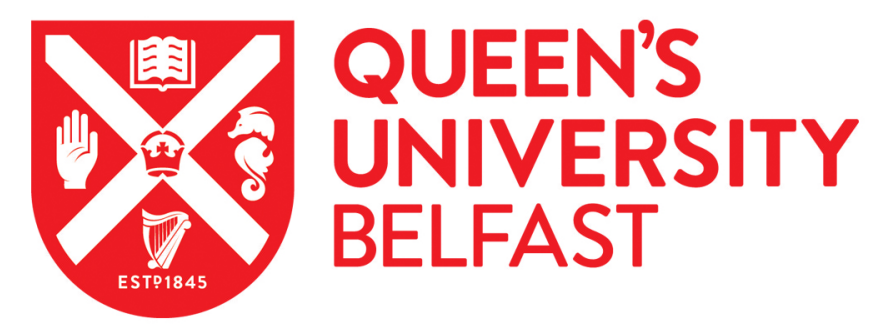

\title{
Deployment of underground coal gasification in India
}

Singan, A., \& Ranade, V. V. (2017). Deployment of underground coal gasification in India. Current Science, 113(2), 218-227. http://www.currentscience.ac.in/php/toc. php?vol=113\&issue $=02$

\author{
Published in: \\ Current Science
}

Document Version:

Publisher's PDF, also known as Version of record

Queen's University Belfast - Research Portal:

Link to publication record in Queen's University Belfast Research Portal

Publisher rights

Copyright 2017 Indian Academy of Sciences. This work is made available online in accordance with the publisher's policies. Please refer to any applicable terms of use of the publisher.

\section{General rights}

Copyright for the publications made accessible via the Queen's University Belfast Research Portal is retained by the author(s) and / or other copyright owners and it is a condition of accessing these publications that users recognise and abide by the legal requirements associated with these rights.

Take down policy

The Research Portal is Queen's institutional repository that provides access to Queen's research output. Every effort has been made to ensure that content in the Research Portal does not infringe any person's rights, or applicable UK laws. If you discover content in the Research Portal that you believe breaches copyright or violates any law, please contact openaccess@qub.ac.uk. 


\title{
Deployment of underground coal gasification in India
}

\author{
Akshay Singan and Vivek V. Ranade*
}

Globally, the sheen of coal-based energy production is slowly wearing, with few exceptions of developing novel technologies that aid in coal gasification and gas clean-up. Underground coal gasification (UCG) is one such tool that can be used for extracting energy contained in otherwise inaccessible reserves. UCG involves the injection of steam and oxidant directly in the seam of coal, which is ignited through different methods. Post-ignition, coal reacts with steam and oxygen to produce a combustible synthesis gas (syn-gas). This syn-gas can be used to generate electricity or utilized as feedstock to take different routes to manufacture chemicals. This paper seeks to briefly outline some aspects in the deployment of underground coal gasification in the Indian subcontinent, along with a discussion on the current status of research in the field. The different stages of identifying and understanding key features and potential roadblocks, based on which decisions on the implementation of large scale UCG in a potential site in India are taken, are briefly outlined. We share our thoughts and experiences on the methodology, to model and understand the process and put forth our suggestions on the path forward.

Keywords. Underground coal gasification, coal seam, pilot experiments, modelling.

UNDERGROUND coal gasification is a technique that can be used to convert the coal present deep within the earth directly into gas. This is done by drilling of holes from the surface till the depth at which the coal is available and igniting the seam. Subsequently steam and oxidizing agent are passed in a controlled manner to sustain gasification which generates synthesis gas, a mixture of carbon monoxide, hydrogen and methane in varying proportions, depending on prevailing conditions. Figure 1 shows an overall schematic of underground coal gasification process. Less than $15 \%$ of global coal reserves are available at depths that deem them recoverable in an economical manner ${ }^{1}$. Indian coal reserves are primarily of the bituminous and lignite stock. These are non-coking coals, which require washing and other up-gradation. There is an estimated reserve of 301.5 billion tonnes of non-coking coal and 43.24 billion tonnes of lignite in India, as of 2014 (ref. 2). Most of the coal reserves have high ash content $(25-60 \%)^{3}$ and are available at depths exceeding $300 \mathrm{~m}$

Akshay Singan is in the Chemical Engineering and Process Development Division, CSIR-National Chemical Laboratory, Pune 411008 , India and also in Academy of Scientific and Innovative Research (AcSIR), CSIR-National Chemical Laboratory (NCL) Campus, Pune 411 008, India; Vivek V. Ranade is in the Academy of Scientific and Innovative Research (AcSIR), CSIR-National Chemical Laboratory (NCL) Campus, Pune 411 008, India and also in School of Chemistry and Chemical Engineering, Queens University of Belfast, Belfast BT9 $5 \mathrm{AG}, \mathrm{UK}$.

*For correspondence. (e-mail: V.Ranade@qub.ac.uk) rendering them less suited for conventional mining techniques ${ }^{4}$.

The advantage of pursuing the option of UCG is that the coal deposit present at great depth need not be removed and brought to surface. India is one of the fastest growing economies in the world and is predominantly driven by coal. Coal-based thermal power plants generate a significant amount of electricity consumed in India (65$70 \%)^{5,6}$. The higher ash content presents a great operational challenge in utilization of domestically mined coal in surface equipment like gasifiers and boilers. Heavy

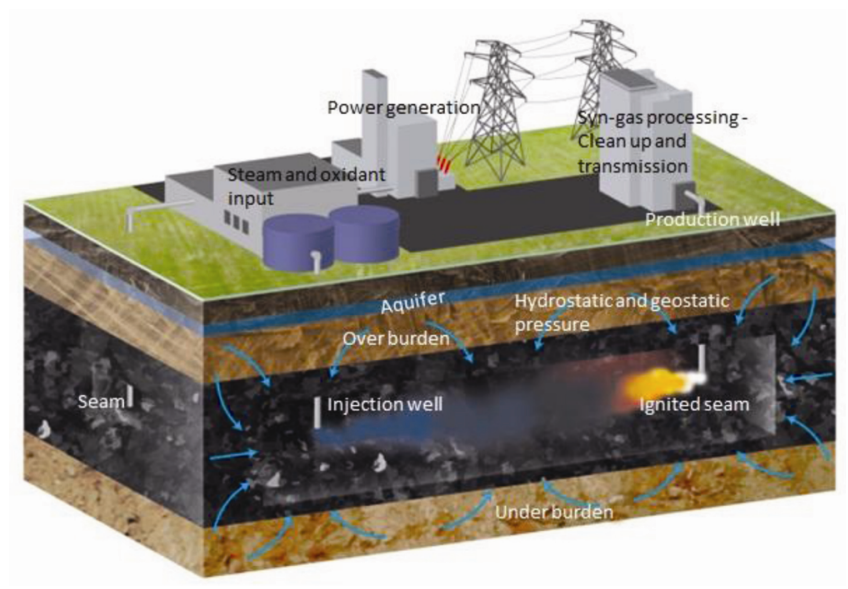

Figure 1. Schematic of UCG process - basic image adapted from Delmo UCG project at Argentina ${ }^{64}$. 
slag formation and ash-based corrosion of the internals have been reported by multiple plant operators ${ }^{3}$. UCG has a unique potential in recovering the heating value from the abundantly available high ash coals through in situ conversion to gas. This can be done at a comparable, if not, lower cost. Other advantages include safer operation unlike shaft mining, significant environmental advantages in reduction of particulate pollution and the possibility of implementing carbon dioxide sequestration and site reclamation and rehabilitation.

Major part of the costs involved in UCG is that of quality geological survey through detailed coring studies conducted through the site, in accordance with standards recommended for the same. The Geological Survey of India and the Central Mine Planning and Design Institute (CMPDI) of India have developed standard techniques in line with the Indian Standards ${ }^{7}$ for this purpose. Standards from American Society for Testing and Materials (ASTM) are also available and are in use globally ${ }^{8}$. Several bodies all over the world have recently evinced interest in carrying out feasibility analysis and have pushed for the possibility of deploying UCG for tapping into coal resources $^{9-12}$. The Ministry of Coal, Government of India has recently initiated a policy on UCG, for recovering gas from the resources of lignite located at great depths ${ }^{13}$. This clearly indicates that in the years ahead there is a possibility that UCG may be adapted for converting coal into gas. This gas can be utilized for power generation or chemicals manufacture. Coal availability as a state-wise breakdown in Indian coal seams is given in Table 1 and that for lignite is given in Table 2. Table 3 lists the several organizations actively involved in research in the field of underground coal gasification, worldwide.

There is considerable interest in the implementation of UCG by multiple parties in India, and they are in the process of getting blocks allocated for development into UCG fields or planning extraction of coal, for surface gasifiers. The new policy on coal has evinced a desire to see blocks specifically utilized for $\mathrm{UCG}^{13,14}$. Table 4 lists some of the potential blocks identified for deployment of UCG in partnership with technology providers. There are several roadblocks in widespread commercialization, like identifying seams with ideal conditions, low controllability and very high level dynamics of operation. The varying quality and quantity of gas, depending on in situ conditions and lack of adequate data that throws light on all of the above factors, are crippling. For running UCG at a potential site, coal seams have to be characterized in detail, before there is any serious deployment of utilities. There are established references for details on the same ${ }^{7,8}$, but we seek to introduce the reader to some of the key tasks in characterizing a site to study its suitability for UCG.

The Ministry of Coal in India has specified guidelines that require that once a coal block is allotted, the prospective operator of the site should study the following characteristics: (i) Permeability of confining strata and coal/lignite seams: This is directly relevant to the flow and diffusion of gas through main channels and over burden.

(ii) Character of joints and faults in coal/lignite seams: Joints and faults are the discontinuities in coal seam that are the result of deposition which are identified based on geological data.

(iii) Geo-mechanical character of coal and associated strata: This comprises coal and strata density, compressive and tensile strength, modules of elasticity, Poisson's ratio, angle of internal friction, cohesion, porosity, permeability ratio, properties of clay and sands, plasticity number and liquid limit for clay and grain size analysis. This data is obtained through coring studies.

(iv) Hydrogeological studies: This comprises subterranean and sub-soil water outlet, hydrodynamic characteristics of aquifer, hydrophysical properties of coal seam and confining strata, chemical composition of groundwater, data on water encroachment into mines and quarries in adjoining areas if any and its drainage measure.

Table 1. Coal resource in billion tonnes-identified within the different states of India (as of 31 March 2015)*

\begin{tabular}{lc}
\hline State/UTs & Total resource \\
\hline Andhra Pradesh & 22.47 \\
Arunachal Pradesh $^{65}$ & 0.09 \\
Assam $^{65}$ & 0.0004 \\
Bihar & 0.16 \\
Chhattisgarh & 52.53 \\
Jharkhand & 80.72 \\
Madhya Pradesh & 25.67 \\
Maharashtra & 10.96 \\
Meghalaya & 0.58 \\
Nagaland & 0.32 \\
Odisha & 75.07 \\
Sikkim & 0.1 \\
Uttar Pradesh & 1.06 \\
West Bengal & 31.32 \\
All India Total & 301.05 \\
\hline
\end{tabular}

*2016 data is yet to be released, and 2015 data is to be used for planning implementation of 2016 coal utilization (Manna et al. ${ }^{2}$ ).

Table 2. Lignite availability in India - variation with depth ${ }^{4}$

\begin{tabular}{lcccc}
\hline \multicolumn{5}{c}{ Geological resource - lignite (billion tonnes) } \\
\hline State & $0-150 \mathrm{~m}$ & $150-300 \mathrm{~m}$ & $>300 \mathrm{~m}$ & Total \\
\hline Tamil Nadu & 5.705 & 8.433 & 20.233 & 34.372 \\
Rajasthan & 1.899 & 3.012 & 0.777 & 5.689 \\
Gujarat & 0.707 & 2.014 & - & 2.722 \\
Puducherry & 0.416 & - & - & 0.416 \\
Kerala & 0.027 & - & - & 0.027 \\
Jammu and Kashmir & 0.009 & - & - & 0.009 \\
West Bengal & 0.001 & 0.001 & - & 0.002 \\
Total & 8.768 & 13.461 & 21.001 & 43.24 \\
\hline
\end{tabular}


Once a coal block has been put up for potential utilization and a decision made regarding allocation, there are detailed guidelines on what data on the block allotted must be determined and provided by the allotted potential operator to facilitate approval for plans to utilize the coal and gas from the site. These are exclusive to the use of the site for UCG, and are besides the regular submissions demanded by the mineral concessions rule of 1960 (ref. 15). Having seen the basis for the UCG option in India and some of the key generic information that is prerequisite for proceeding on identifying and utilizing a site that is suitable for UCG, there is a need to understand the key factors that influence the UCG process from an engineering and operational point of view.

\section{Key factors influencing UCG}

Some of the key relevant factors are briefly discussed in the following section.

Chemical composition of coal: Volatile matter, moisture and ash content have the primary effect on gasification reaction $^{16-19}$. Several studies have been published on coal analysis (see for example refs 20,21).

Depth: Coal seam depth is one of the important cost determining parameters in UCG. Coal seams at shallow depth (depth of up to $300 \mathrm{~m}$ ) are generally easier to ignite. For coal seams at a depth of greater than $300 \mathrm{~m}$, the risk of surface subsidence and sink holes is significantly reduced. Vertical separation of more than $100 \mathrm{~m}$ from the major aquifers is preferred ${ }^{22}$.

Thickness: Seam thickness of more than $1 \mathrm{~m}$ is preferred $^{23,24}$. A thinner coal seam (anything less than $0.5 \mathrm{~m}$ ) in UCG are beset with problem with possible discontinuities in the seam and heat losses.

Dip/angle of inclination of seam: Dipping (greater than $70^{\circ}$ ) coal seams is easy to sustain and ignites easily when compared to horizontal seams ${ }^{25}$.

Coal rank and properties: Low rank (lignite and subbituminous) and non-swelling coals are mostly preferred for UCG process ${ }^{25}$ as they shrink upon heating, thus enhancing the permeability.

Table 3. Key institutions worldwide with UCG technology know-how/ active UCG research

\begin{tabular}{ll}
\hline Institution & \multicolumn{1}{c}{ Country } \\
\hline Ergo Exergy & USA and Canada \\
Linc Energy Pvt. Ltd. & Australia \\
Carbon Energy & Australia \\
Lawrence Livermore National Laboratory, & \\
$\quad$ California & USA \\
CSIRO, Australia & Australia \\
China University of Mining and Technology & China \\
Indian Institute of Technology, Bombay & India \\
CSIR - National Chemical Laboratory & India \\
\hline
\end{tabular}

Permeability of coal: Permeability is the ability of pores or cracks present in coal to permit transport of fluids. In general, high rank coals and at a greater depth have low permeability. Permeability is important in UCG; better cleated and more permeable coal seams easily allow the transport of reactant and product gases during gasification process.

Feed quality: The oxidant and steam/moisture flow rate and composition (steam: oxidant), and the potential use of fire retardant in the case of lack of controlled gasification, are all quite relevant from operation and safety perspective.

Site hydrology: Water is needed for the UCG process because it plays an important part in the gasification reaction. Good understanding of hydrology of a potential UCG site is important ${ }^{25}$.

The parameters and the value/range of values generally desired for large scale UCG operations, gathered from multiple field trials, are listed in Table 5. In order to deploy UCG, it is essential to develop quantitative understanding by analysing the relationships between parameters mentioned above and the measurable performance of a UCG field under consideration. Quantitative mathematical models validated by laboratory and pilot/field scale experiments are needed for this purpose. Despite the immense potential UCG holds for India, there is still a lack of coherent research effort. We discuss in brief key research requirements and current status in the following sections.

\section{Modelling of UCG for successful deployment: status in India}

A process as complex as coal gasification is challenging on multiple levels. The several methodologies of modelling and experimentation that were developed for surface level gasification have greatly helped increase the current levels of understanding. This knowledge must be leveraged in a smart manner to build tools for analysing the underground reactor.

To begin with one must identify the differences between a surface gasifier and an underground reactorbeginning with varying volume as UCG progresses, loss of heat and valuable syn-gas to the surrounding layers of strata, and the potential instabilities in gas production in terms of quality and quantity. Small changes in process conditions, within the seam and cavity (underground reactor), can significantly influence rate of gasification, which is usually experimentally studied and reported on a single particle basis. Studies considering the reaction kinetics and source terms while dealing with the seam as porous media using a single-step decomposition method and analysing the role of frequency factors and activation energies of several reactions have been undertaken ${ }^{26,27}$. Recently even the pyrolysis and the use of $\mathrm{CO}_{2}$ as a 
GENERAL ARTICLES

Table 4. Coal blocks allotted to major PSUs in India for development into UCG fields

\begin{tabular}{|c|c|c|}
\hline $\begin{array}{l}\text { Oil and Natural Gas Corporation (ONGC) }+ \text { NMRC }- \text { Skochinsky } \\
\text { Institute of Mining, Russia }+ \text { Gujarat Industries } \\
\text { Power Company Limited (GIPCL), Gujarat }{ }^{60}\end{array}$ & Lignite & Vastan Site, Gujarat \\
\hline $\mathrm{ONGC}^{60}$ & Lignite & Kasta Block, Raniganj \\
\hline $\begin{array}{l}\text { Coal Indial Limited (CIL) }- \text { Abhijeet Group }+ \text { Ergo Exergy }^{66} \\
\text { CMPDI + CIL }\end{array}$ & Inferior coking coal & $\begin{array}{l}\text { Kaitha block - Ramgarh Coal fields of CCL } \\
\text { Thesgora C Block in Pench-Kanhan Coal fields of WCL }\end{array}$ \\
\hline GAIL + Ergo Exergy ${ }^{37,38}$ & Lignite & Barmer, Rajasthan \\
\hline $\begin{array}{l}\text { Centre for Mine Planning and Development India (CMPDI) + } \\
\text { Coal India Limited (CIL) }\end{array}$ & Coal & Yellendu (Dip side), Telangana \\
\hline $\mathrm{CMPDI}+\mathrm{CIL}^{68}$ & Coal & BandhaSingrauli Main Basin, MP \\
\hline $\mathrm{CMPDI}+\mathrm{CIL}^{68}$ & Lignite & Sindhari West, Barmer, Rajasthan \\
\hline $\mathrm{CMPDI}+\mathrm{CIL}^{68}$ & Lignite & Chokla North, Barmer, Rajasthan \\
\hline CMPDI + CIL $^{68}$ & Lignite & Nimbalkot, Barmer, Rajasthan \\
\hline CMPDI + CIL $^{68}$ & Lignite & Nagurda, Barmer, Rajasthan \\
\hline CMPDI + CIL $^{68}$ & Lignite & Dungra, Surat, Gujarat \\
\hline
\end{tabular}

Table 5. Desired specifications for the implementation of underground coal gasification on field scale ${ }^{69}$

\begin{tabular}{|c|c|}
\hline Parameter & Desired value \\
\hline Coal thickness (m) & $1.5-25$ \\
\hline Thickness variation (\% Seam thickness) & $<25$ \\
\hline Depth $(\mathrm{m})$ & $100-500$ \\
\hline Dip (degrees) & $0-70$ \\
\hline Dip variation (degrees per $31 \mathrm{~m}$ depth) & $<2$ \\
\hline Single parting thickness $(\mathrm{m})$ & $<1$ \\
\hline Total parting thickness (\% of seam thickness) & $<20$ \\
\hline Fault displacement (\% of seam thickness) & $<25$ \\
\hline Fault density & $<1$ \\
\hline Coal rank & $\leq$ Bituminous, lignite \\
\hline Coal moisture (wt\%) & $<15$ \\
\hline Ash content $(w t \%)$ & $\begin{array}{l}<50-\text { High ash coals that can't be used in surface } \\
\text { gasifiers are preferred }\end{array}$ \\
\hline Coal sulphur (wt\%) & $<1-$ greater value will require mandatory $\mathrm{SO}_{x}$ clean up \\
\hline Thickness of consolidated over-burden (m) & $>15-$ Any lesser value increases the risk of subsidence \\
\hline Seam permeability $(\mathrm{mD})$ & $50-150$ \\
\hline Immediate over burden permeability (mD) & $<3-5$ \\
\hline Distance to nearest overlying water bearing unit (m) & $\begin{array}{l}>31-\text { Based on water quality logging done in bore } \\
\text { holes to test water quality }\end{array}$ \\
\hline Coal aquifer characteristics & Confined \\
\hline Nearest producing well completed in coal seam $(\mathrm{km})$ & $>1.6-$ in pilot scale $-18-20 \mathrm{~m}$ \\
\hline Available resource for conversion $\left(\mathrm{m}^{3}\right)$ & $15,400,000$ \\
\hline
\end{tabular}

gasifying agent have been tested in sub-bituminous coal as well as lignite ${ }^{28-31}$. Even the modelling of species diffusion for $\mathrm{CO}_{2}$ gasification in the UCG context, for single particle basis using TGA study of $\mathrm{CO}_{2}$ gasification has been studied and reported ${ }^{32}$. The means for monitoring and control of conditions prevailing underground are limited. Herein lies the role of mathematical modelling. Models can be developed on multiple scales, covering different details from several hypotheses on how the process of UCG proceeds. Data obtained from the computational solution for these models under different conditions must be validated by comparing with data from experimental studies with similar conditions. With adequate confidence in the model's predictions, one can then use it to extrapolate to different operating horizons in order to identify the best set of conditions for a particular coal quality. Key processes occurring in the UCG field and key design details with respect to layout of a UCG field are shown schematically in Figure 2. It is difficult to control the combustion zone in the UCG scenario. The roof part in the zone of gasification gets consumed slowly and there are several fractures that form slowly and continuously, through continuous exposure of coal to high temperature. This happens due to repeated swelling of the low rank coal. Pieces of coal fall down with ash, after breaking from the continuous seam to collect at the bottom of the seam in the form of a rubble layer. This act of breaking down of the seam due to thermal and mechanical stresses is termed as spalling. There is also the diffusion of water (from the surrounding aquifers) along with the incoming reactants and generated product gases through the over burden and the porous seam to the gasification zone. The 
heat generated from partial and full oxidation of coal in turn drives the drying and devolatilization further down the seam. A complex nature of heat transfer including all modes - conduction, convection and radiation - occurs within the seam which needs to be incorporated realistically into the energy balance, along with losses. The synthesis gas generated in the underground reactor is transported to the surface for clean-up and utilization through the production well.

In order for us to realize this potential of UCG and for safe extraction of value from otherwise inaccessible resources, implementation has to be preceded by the development of a level of expertise in geological characterization, characterization of coal cores and accuracy in estimating the quantity of resource available for conversion. We must also develop significant expertise in multiple modes of drilling. Subsequently we must develop a level of proficiency and confidence in developing models and evaluating the data obtained and transforming it into understanding. Such learning can then be used for making improvements to aid improved process safety and performance.

Several research groups around the world have done extensive work in developing experimental and computational studies to gain better understanding on the different stages of UCG. This is especially true in countries rich in coal reserves like China, South Africa, USA, some countries of the European Union (EU), Australia and India. There has been considerable kindling of interest in the field, with the identification of science and technology gaps in underground coal gasification ${ }^{23}$ and best practices in underground coal gasification ${ }^{25}$. There is still a lack of a comprehensive modelling strategy to cover all the stages of UCG and the absence of reliable experimental or field scale data for validation of the developed model. This fills the lacunae in our understanding. Several
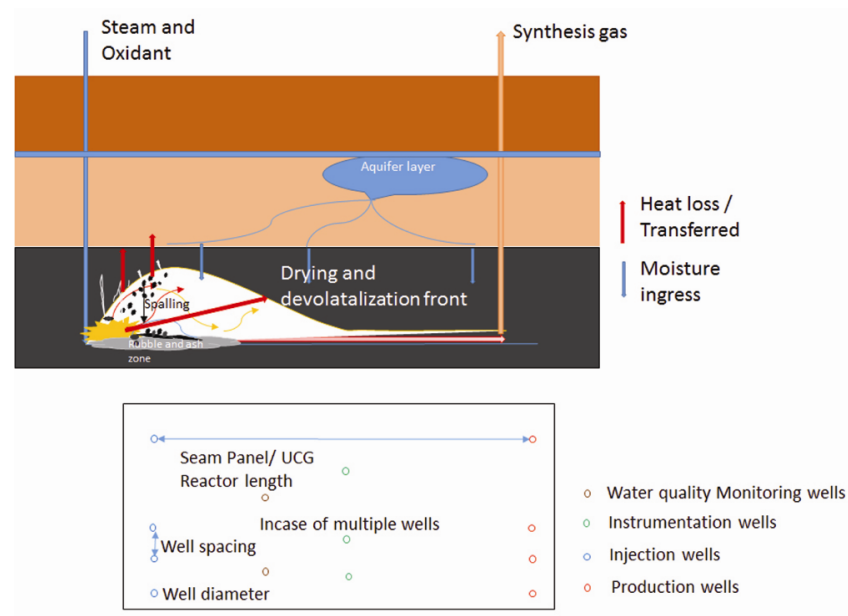

Figure 2. UCG participant phenomena within a single cavity scaled up to commercial scale configurations and novel configurations that can potentially optimize resource recovery. reviews have been published over the years to help in tracking the progress in research on $\mathrm{UCG}^{33-35}$.

The focus here is on Indian UCG research. Mahajani and his group at IIT Bombay in collaboration with ONGC have carried out experimental and simulation studies for application of UCG to Indian coals. Research groups at CSIR-CIMFR in partnership with other NIET and IIT Kharagpur have carried out feasibility analysis of UCG in the northeastern region of India, establishing a database on coals available in northeast India. A repository of information on the multiple aspects of UCG has been collected and summarized in an accessible form through a website. CSIR-CIMFR, NIET and IIT Kharagpur have also developed techniques for determining gas concentration within the coal seam and equipment for measuring methane concentration in mines underground and measuring roof strength ${ }^{36}$. The group at CSIR-NCL has contributed to coal combustion, fluidized bed gasifier as well as UCG. Work on UCG was carried out in collaboration with GAIL team. GAIL has been one of the major components in the pursuit of commercial scale UCG since 2005 when it initiated work on UCG at Barmer in Rajasthan in collaboration with Ergo Exergy of Canada ${ }^{37,38}$. Kinetic modelling of heterogeneous reactions is carried out using thermogravimetric analysis (TGA) ${ }^{39}$. TGA yields the loss of weight with time under different conditions of temperature and pressure when the particles are stationary. It is a method that has gained relevance for determining kinetic parameters of different stages of coal combustion and gasification. The group at CSIR-NCL has developed systematic analysis of model based fitting methods based on iso-conversional strategies and have provided a detailed framework for choosing the methodology to use for processing thermogravimetric data ${ }^{40}$. Alternatively, a drop tube furnace (DTF) in which the particle travels a fixed distance of space maintained at specified conditions, with the particle being analysed before and after being dropped through, is used to characterize coal combustion and gasification kinetics. Ranade and Gupta ${ }^{41}$ have brought out the need for using detailed CFD models for interpreting the data generated by DTF. TGA/DTF data can be used to understand various reactions of coal with oxygen and steam and their kinetics. It is important to estimate spalling rates under different operating conditions in order to identify and quantify the influence that spalling phenomena has on the process. Experimental methods for characterizing spalling of coal have been developed in micro UCG scale, along with model based insights into the development of the reactor zone $^{42}$.

The IITB group has carried out experimental measurements of cavity formation and development of different operating conditions in micro-UCG. A correlation was developed to quantify the impact of operating conditions on cavity shape and size, while simultaneously measuring the gas composition at the outlet ${ }^{43}$. The group at IIT 


\section{Equilibrium modelling of UCG}
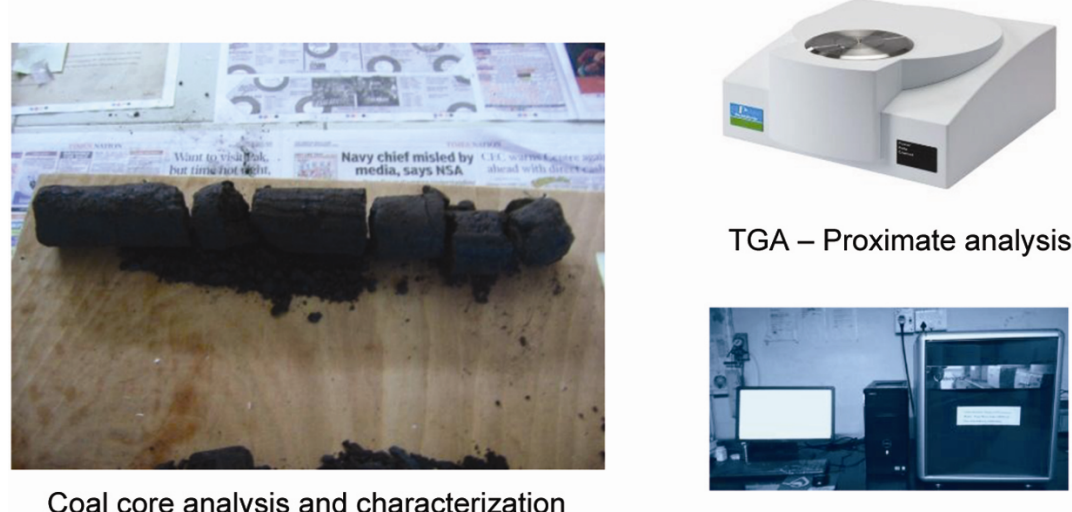

TGA - Proximate analysis

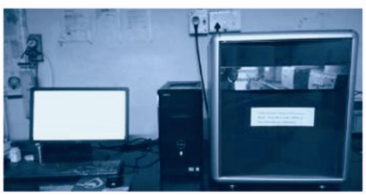

Ultimate analysis

Thermodynamic modelling - composition of Syn-gas at the outlet - estimate of gross calorific value (GCV)

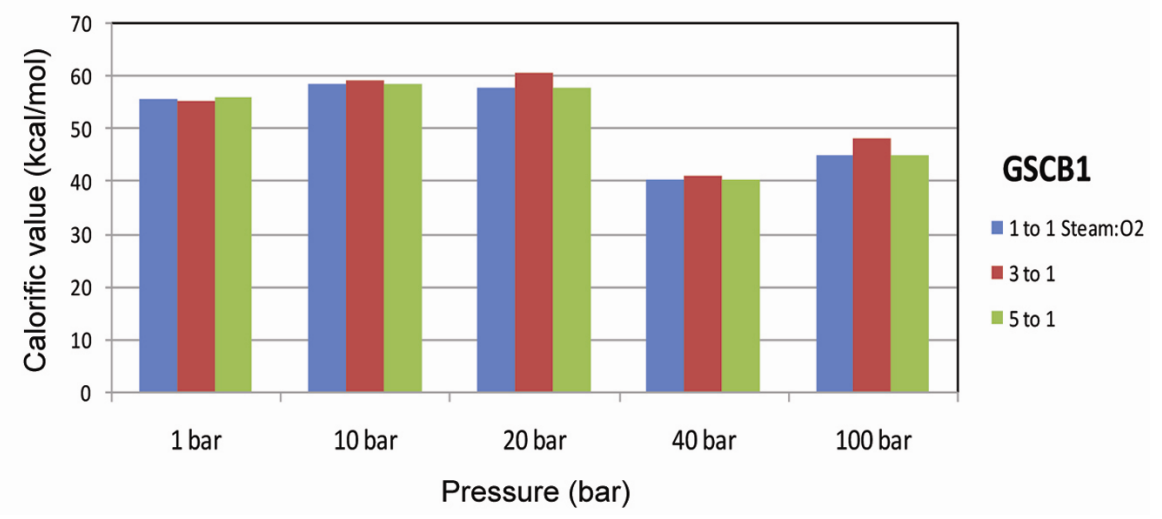

Figure 3. Equilibrium modelling of UCG.

Madras carried out experimental study on the cavity development through borehole experiments in blocks of wood, coal and camphor ${ }^{44}$. Process models for evaluating endpoint use of syn-gas in a SOFC system in a combined cycle system were developed ${ }^{45}$.

Development of steady state and dynamic models for computational analysis of the UCG reactor and detailed characterization of flow within the cavity have been reported $^{46}$. This has happened alongside experimental analysis of the same ${ }^{43}$. CFD modelling of the underground coal gasification can be used to understand how the configuration of the well and its placement through the site can affect cavity development. It may also be used to characterize mixing and the residence time distribution (RTD) within the cavity. This is key for breaking down complex flow in the underground reactor into a sequence of reactors of ideal flow conditions, that form a network representing the entire seam and this has been done for a micro-UCG scenario ${ }^{6,43,46}$. This approach can yield models that significantly reduce burden on computational resources. The group at CSIR-NCL proposed a comprehensive three-layered approach and developed a modelling framework for simulating several reaction and transport processes during UCG. Our approach is repre- sented schematically in Figures 3-5. Detailed physicochemical characterization of samples duly obtained from coal cores and blocks revealed the basic content of coal. Information on coal composition obtained from this was used in the thermodynamic modelling of UCG (based on the minimization of Gibbs-free energy). This exercise yielded the equilibrium composition of synthesis gas with variation in feed quality for specified conditions of temperature and pressure in gasification (Figure 3). Subsequently a reactor model based on mass and energy balances (without considering momentum balances) accounting for key combustion and gasification reactions was developed ${ }^{47}$. This was a one-dimensional reactor model, in which all the mass and energy balances took the form of ordinary differential equations. Different input and kinetic parameters were vetted out and the predictions were compiled (Figure 4). The model was validated by comparing model predictions with experimental data in published literature. The experimental results of gas composition and the cavity sizes, from the group at IIT Bombay ${ }^{6}$ were especially useful in carrying out this exercise. Detailed CFD modelling of the coal block under UCG conditions and operation was done to account for features which are difficult to represent in conventional 


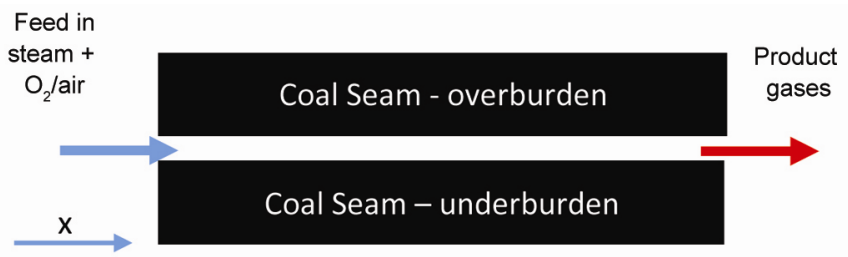

1D-ODE model - input parameter variation and optimization tool for CFD modelling parameters Comparison with published results/available data
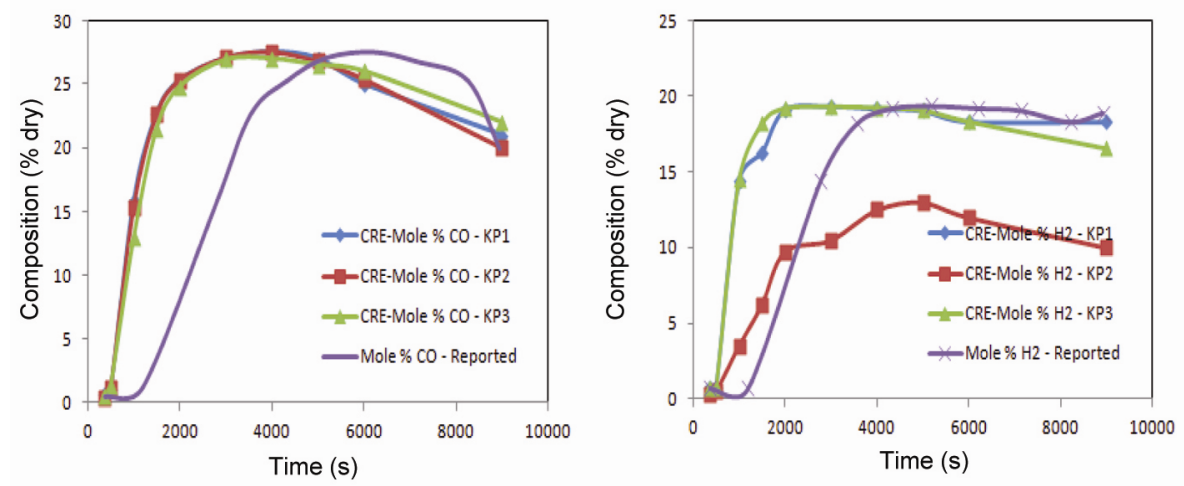

Figure 4. Reaction engineering model for UCG.

reaction engineering models. Current level of analysis has yielded the characterization of flow pattern within a standard micro-UCG cavity, backed with experimental tracer analysis. On a large scale, CFD modelling takes a long time and significant computational resources. The effects of several contributing factors like kinetic parameters, permeability, diffusion rates, inlet and outlet design and conditions, on the gas quality and quantity on an overall block basis can be studied here. It is a step forward in going towards the ability of being able to put a reliable number on rate of recession of the coal front for set kind of coal and design of inlet and outlet wells (Figure 5).

It will be useful to include brief comments about the worldwide UCG research to provide a context for the preceding discussion. The Lawrence Livermore National Laboratory and the US-DOE have developed a significant level of modelling and experimental expertise in UCG, including the publication of data from soviet trials of $\mathrm{UCG}^{48-50}$. Several field trials and modelling studies have been published over the 1970s and 1980s (ref. 33). The 1990 decade when large scale availability of cheaper and relatively cleaner oil and natural gas was available led to reduced interest in UCG research.

A summary report from the working group on UCG identified that there is a $20-30 \%$ saving in capital expenses if UCG route is preferred over the IGCC route a $100 \mathrm{~mW}$ power plant $^{38}$. Recent reports from Australia have covered the operational aspects and key learnings from deploying technologies to undertake UCG on a pilot demonstrative scale at Chinchilla ${ }^{51}$. Cursory data on the five gasifiers have been made available in this work. The same group in another recent paper reported on the viability of UCG for coal-rich developing nations, and have published that the overall thermal efficiency coupled with potential for lower $\mathrm{CO}_{2}$ emissions along with reduced capital expense makes UCG a pursuable option ${ }^{52}$. A research group from North Dakota (USA), where UCG was supposed to be initiated has reported on the cost effectiveness and viability of an operational UCG gasifier $^{53}$. An exercise of similar nature has been reported by a group from Slovenia ${ }^{54}$. Detailed geo-mechanical modelling of underground coal gasification with CRIP approach has been reported, with the effects of high temperature and the evolution of the cavity, for varying models like linear, elasto-plastic and hyperbolic representation of the stress imbalances within the seam ${ }^{55}$. A major report on the viability and economics of UCG recently appeared in Australia, where the need for caution before proceeding for the deployment of UCG route and the several potential troubles have been brought forth clearly ${ }^{56}$.

Fluctuations in oil and gas price and supply complemented by a standing reminder of the need to utilize abundantly available coal, with newer and efficient routes for gas clean-up have renewed the interest in UCG as a clean coal technology. Although many studies are available, comprehensive data on field trials is often unavailable in open literature making validation on a large scale nearly impossible.

There are several key technology providers that have implemented UCG on a commercial scale and have developed hands on expertise in deploying and operating UCG. This is crucial for generating data and furthering 
the interest in UCG. Field trials give key insights into the operational aspects of running UCG on a large scale. The fact that there are several successful cases where large scale implementation of UCG definitely boosts confidence in technology and stands as are minder that it is possible to safely deploy $\mathrm{UCG}^{24,57}$. Table 3 lists the major private and publicly funded institutions actively pursuing research in UCG. Several universities also have research groups pursuing some facets of the UCG problem.

Given the relevance of the potential that UCG holds in enabling India to become self-reliant from an energy perspective, a coherent nation-wide research programme to develop better understanding and tools for design and evaluation of UCG operation are needed. It is essential to develop capability and tools for:

(a) Characterization of coal heterogeneity and reactivity: Extensive resource quantification and detailed characterization are essential for quantifying commercial potential and deployment of UCG. Data on spalling characteristics of coal seams as a function of pressure, temperature and environment are not available. It is important to generate this data through well-designed experiments and pilot trials. More data on reactivity is needed for developing reliable computational models for simulating UCG.

(b) Data from laboratory, pilot and field scale experiments: Better measurement techniques for monitoring in situ conditions and analysis of post-gasification effects are needed. For example, tomography has been used for investigating flow in cores under conditions resembling fracking for shale gas ${ }^{58,59}$. Such tools may provide new insights into spalling rates and cavity development of UCG. ONGC is working towards pilot scale trials at their

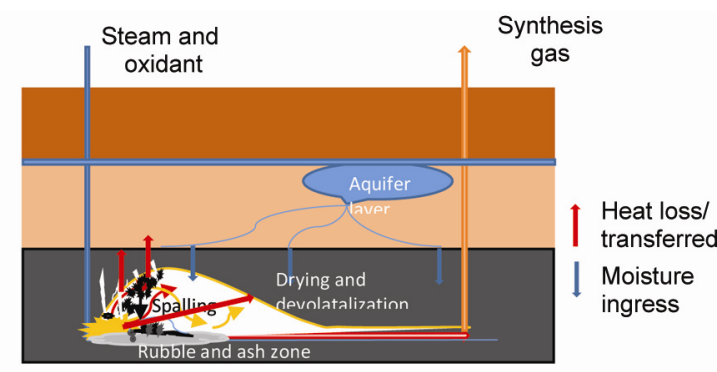

3D Reactor model - momentum term Detailed modelling of flow pattern -

use of information from reaction engineering model

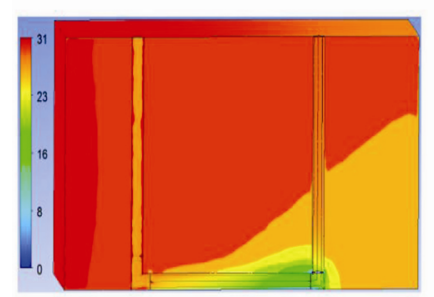

Carbon monoxide

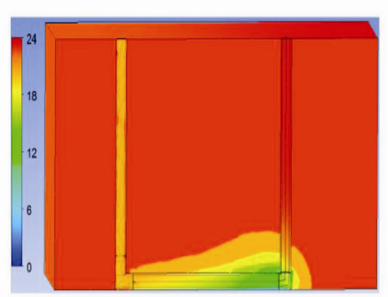

Hydrogen
Figure 5. CFD modelling of UCG.
Vastan site in Gujarat ${ }^{60}$. Safe drilling techniques and operational protocols covering most contingencies, along with effective use and preservation of groundwater quality are essential for UCG to be successful. Experimental data on environmental impact, particularly on groundwater pollution is needed. Remediation strategies for mitigating potential environmental impact need to be developed. Possible use of UCG wells and cavity for purposes like carbon dioxide sequestration need to be explored.

(c) Improving reliability of computational models of UCG: It is important to account for key aspects like geomechanics, radiative heat transfer coupled with gas solid heterogeneous reaction, flow, heat transfer and mixing for reliably, simulating UCG process. Multi-layer approach used by the group at CSIR-NCL can be extended to include additional factors. Appropriate framework needs to be developed to exchange information from different modelling layers so as to develop a comprehensive UCG simulation tool with adequate reliability. It is also important and essential to couple such phenomenological models with the life cycle and cost analysis for assessing the overall economic and environmental impact of the UCG site/operation.

UCG guarantees resource recovery, even for very poor quality of solid fuel, of which India has abundant reserves. The wells are the size of bore wells and are sealed and cemented post-use. There is minimal damage to the surface, which can be restored to its original state. The potential of ensuring the safety of workers, which is often constantly under threat in conventional mining methods is definitely relevant to Indian mining where safety against hazards is important. The cavity can be used later for storage of $\mathrm{CO}_{2}$ for sequestration purposes. Potential threats from UCG include leakage of gases into aquifers, loss of energy, sinkhole formation and ground subsidence. All these are manageable when there is proper selection of site on the basis of the summary in Table 5. Through accurate and useful models, developed alongside insights from experiments on multiple scales, one can most certainly arrive at the stage where confidence in operability is established. Awareness must be created on the need for safe operation of $\mathrm{UCG}^{61}$, highlighting among the general public and responsible authorities, the need for safe utilization of our coal reserves to move towards self-reliance.

A new policy framework for development of underground coal gasification in coal and lignite bearing areas in India has been approved. It is on the lines of the existing policy for coal bed methane (CBM) ${ }^{62}$ and gas hydrate programme $^{63}$ on revenue sharing basis and blocks have already been identified for UCG (Table 4). Companies in India (PSUs and private companies) must prioritize the monetization and value generation from indigenous coal reserves through generation of synthesis gas. Adequate hands-on experience with emphasis on safe and environmentally benign operation, can give us the ability to 
deploy UCG on a commercial scale. This can be made possible through a transparent and mutually beneficial exchange of useful and relevant information from previous experiences. This would go a long way in helping India reach its goal in utilizing indigenous coal through UCG. The resources and capital to build good level of understanding of the process and transform that learning into working practice, can most certainly spur the development of UCG. A formal national mission programme on the lines of that carried out for assessment and development of gas hydrates as a potential energy source by the oil industry development board ${ }^{62}$, and the Ministry of Earth Sciences ${ }^{63}$ can be one way to get a synergy between industry and academia. Clearly laid out mission mode project which brings together critical mass of expertise and experience from academia and industry is needed for deploying UCG on commercial scale in India.

\section{Summary}

This paper highlighted that UCG offers a great opportunity to gain self-reliance in energy generation and creates value from otherwise inaccessible resources in India. We have summarized some of the basic information needed for identifying a potential site for UCG and key variables and parameters influencing UCG. We have briefly reviewed past and current research on UCG with particular emphasis on Indian groups. Some areas where further work is needed were outlined. A need for establishing a coherent nation-wide programme with clearly defined objectives was highlighted. This will facilitate deployment of UCG on commercial scale in India which will be a significant step towards the national aspiration of self-reliance in energy.

1. World Energy Council, London, Report on World Energy Resources, 2016, pp. 61-63.

2. Manna, G. C., Chhabra, B. S., Rathore, G. S., Kumar, S. and Hada, A. S., Energy Stat., 2015.

3. Mehra, A., Farago, M. E. and Banerjee, D. K., Impact of fly ash from coal-fired power stations in Delhi, with particular reference to metal contamination. Environ. Monit. Assess., 1998, 50, 15-35.

4. Khadse, A. N., Resources and economic analyses of underground coal gasification in India. Fuel, 2015, 142, 121-128.

5. Khadse, A. N., Underground Coal Gasification: Kinetics and Process Modeling, thesis, Department of Chemical Engineering, Indian Institute of Technology, Bombay, 2007.

6. Daggupati, S., Underground Coal Gasification: Experimental Studies and Computational Flow Modeling, Ph D thesis, IIT Bombay, 2010.

7. Geological Survey of India, Coal, Lignite and CBM Exploration: Standard Operational Procedure, 2010; http://www.portal. gsi.gov.in/gsiDoc/pub/sop coal lignite final.pdf

8. Luppen, J. A., Wilson, S. E. and Stanton, R. W., ASTM Manual on Drilling, Sampling and Analysis of Coal, 1992; https://doi. org/10.1520/MNL11-EB.

9. Shackley, S., Mander, S. and Reiche, A., Public perceptions of underground coal gasification in the United Kingdom. Energy Policy, 2006, 34, 3423-3433.
10. Pana, C., Review of Underground Coal Gasification with Reference to Alberta's Potential. Report, Alberta Geological Survey, Energy Resources Conservation Board, 2009.

11. Mastalerz, M., Drobniak, A., Parke, M. and Rupp, J., Site evaluation of subsidence risk, hydrology and characterization of Indiana coals for underground coal gasification. Report from Centre for Coal Technology Research, Purdue University, IN, USA, 2011.

12. Pei, P. et al., Investigation of the feasibility of underground coal gasification in North Dakota, United States. Energy Convers. Manage., 2016, 113, 95-103.

13. Press Information Bureau, Policy Framework for development of Underground Coal Gasification in coal and lignite bearing areas in India. Press Information Bureau, Government of India, 2015; http://pib.nic.in/newsite/PrintRelease.aspx?relid=133405.

14. Press Information Bureau - Ministry of Coal, Steps for Development of Underground Coal Gasification Technology, 2015; http://pib.nic.in/newsite/PrintRelease.aspx?relid=132935.

15. Controller General, Indian Bureau of Mines. Mineral Concession Rules, 1960 (October 2012), Nagpur.

16. Duan, T. H., Lu, C. P., Xiong, S., Fu, Z. Bin and Chen, Y. Z., Pyrolysis and gasification modelling of underground coal gasification and the optimization of $\mathrm{CO}_{2}$ as a gasification agent. Fuel, 2016, 183, 557-567.

17. Gomez, A. and Mahinpey, N., Kinetic study of coal steam and $\mathrm{CO}_{2}$ gasification: a new method to reduce interparticle diffusion. Fuel, 2015, 148, 160-167.

18. Naidu, V. S., Aghalayam, P. and Jayanti, S., Evaluation of $\mathrm{CO}_{2}$ gasification kinetics for low-rank Indian coals and biomass fuels. J. Therm. Anal. Calorim., 2016, 123, 467-478.

19. Samdani, G. et al., Diffusion Modeling in TGA in Context of $\mathrm{CO}_{2}$ Gasification of Char. In Proceedings of the 2012 COMSOL Conference, 2012, pp. 1-6.

20. Petrakis, L. and Grandy, D. W., Coal analysis, characterization and petrography. J. Chem. Educ., 1980, 57, 689.

21. Xie, K. C., Structure and Reactivity of Coal: A Survey of Selected Chinese Coals, Book section, 2015, pp. 1-413; doi:10. 1007/978-3-662-47337-5.

22. Mastalerz, M., Drobniak, A., Parke, M. and Rupp, J., Site evaluation of subsidence risk, hydrology and characterization of Indiana coals for underground coal gasification. Report from Centre for Coal Technology Research, Purdue University, IN, USA, 2011.

23. Upadhye, R., Friedmann, J. and Burton, E., Best Practices in Underground Coal Gasification. Report, Lawrence Livermore National Laboratory, CA, USA, 2007.

24. Underground Coal Gasification-Project management and co-ownership (Presentation) Clean Coal Limited, 2009.

25. Upadhye, R., Friedmann, J. and Burton, E., Best Practices in Underground Coal Gasification, LLNL, California, 2007.

26. Seifi, M., Simulation and Modeling of Underground Coal Gasification Using Porous Medium Approach. Ph D thesis, University of Calgary, 2013; http://doi.org/10.1017/CBO9781107415324.004.

27. Seifi, M., Chen, Z. and Abedi, J., Reaction rate constants in simulation of underground coal gasification using porous medium approach. Mitigation Adap. Strat. Global Change, 2016, 21(4), 645-662; https://doi.org/10.1007/s11027-014-9582-3.

28. Molina, A. and Mondragón, F., Reactivity of coal gasification with steam and $\mathrm{CO}_{2}$. Fuel, 1998, 77, 1831-1839.

29. Duan, T. H., Lu, C. P., Xiong, S., Fu, Z. Bin and Chen, Y. Z., Pyrolysis and gasification modelling of underground coal gasification and the optimisation of $\mathrm{CO}_{2}$ as a gasification agent. Fuel, 2016, 183, 557-567.

30. Gomez, A. and Mahinpey, N., Kinetic study of coal steam and $\mathrm{CO}_{2}$ gasification: A new method to reduce interparticle diffusion. Fuel, 2015, 148, 160-167.

31. Naidu, V. S., Aghalayam, P. and Jayanti, S., Evaluation of $\mathrm{CO}_{2}$ gasification kinetics for low-rank Indian coals and biomass fuels. J. Therm. Anal. Calorim., 2016, 123, 467-478. 
32. Samdani, G. et al., Diffusion modelling in TGA in context of $\mathrm{CO}_{2}$ gasification of char. In Proceedings of the 2012 COMSOL Conference, 2012, pp. 1-6.

33. Gregg, D. W., Underground coal gasification. AIChE J., 1978, 24, 753-781.

34. Shafirovich, E. and Varma, A., Underground coal gasification: a brief review of current status. Ind. Eng. Chem. Res., 2009, 48, 7865-7875.

35. Bhutto, A. W., Bazmi, A. A. and Zahedi, G., Underground coal gasification: from fundamentals to applications. Prog. Energy Combust. Sci., 2013, 39, 189-214.

36. Chaulya, S. K., Singh, A. K., Misra, S. and Saikia, P., Development of Feasibility Assessment Model for Adaptation of Underground Coal Gasification Technology in North East Region of India. New Delhi, 2013

37. Ergo Exergy-GAIL-UCG in India, 1999; http://www.ergoexergy. com/about_us_ourb_projects_gail.htm

38. Working Group on Underground Coal Gasification. Status Report on Underground Coal Gasification. Office of the Principal Scientific Advisor to the Government of India, 2007.

39. Mandapati, R. N. et al., Experiments and kinetic modelling for $\mathrm{CO}_{2}$ gasification of Indian coal chars in the context of underground coal gasification. Ind. Eng. Chem. Res., 2012, 51, 1504115052 .

40. Jain, A. A., Mehra, A. and Ranade, V. V., Processing of TGA data: analysis of isoconversional and model fitting methods. Fuel, 2016, 165, 490-498.

41. Ranade, V. V. and Gupta, D. F., Computational Modelling of Pulverized Coal Fired Boilers, CRC Press, 2014.

42. Bhaskaran, S. et al., Experimental studies on spalling characteristics of Indian lignite coal in context of underground coal gasification. Fuel, 2015, 154, 326-337.

43. Daggupati, S. et al., Laboratory studies on combustion cavity growth in lignite coal blocks in the context of underground coal gasification. Energy, 2010, 35, 2374-2386.

44. Prabu, V. and Jayanti, S., Simulation of cavity formation in underground coal gasification using bore hole combustion experiments. Energy, 2011, 36, 5854-5864.

45. Prabu, V. and Jayanti, S., Underground coal-air gasification based solid oxide fuel cell system. Appl. Energy, 2012, 94, 406-414; doi:10.1016/j.apenergy.2012.01.040.

46. Daggupati, S. et al., Compartment modelling for flow characterization of underground coal gasification cavity. Ind. Eng. Chem. Res., 2011, 50, 277-290.

47. Ranade, V. V., Development of Modeling Framework for Underground Coal Gasification, Report Submitted to GAIL, 2015

48. The Podmoskovnaya Underground Coal Gasification Station, Report LLNL, 1963.

49. Stephens, D. R., Hill, R. W. and Borg, I. Y., Underground Coal Gasification Review. UCRL 92068 - Presented at the 18th Annual Oil Shale Symposium. Denver, Colorado, 1985.

50. Olness, D., The Angrenskaya Underground Coal Gasification Station. Report LLNL UCRL-53300, 1982.

51. Perkins, G., du Toit, E., Cochrane, G. and Bollaert, G., Overview of underground coal gasification operations at Chinchilla, Australia. Energy Sources, Part A Recover. Util. Environ. Eff., 2016, 38 3639-3646.
52. Doucet, D., Perkins, G., Ulbrich, A. and du Toit, E., Production of power using underground coal gasification. Energy Sources, Part A Recover. Util. Environ. Eff., 2016, 38, 3653-3660.

53. Pei, P. et al., Investigation of the feasibility of underground coal gasification in North Dakota, United States. Energy Convers. Manag., 2016, 113, 95-103.

54. Praunseis, Z., Avsec, J., Pohar, A. and Medved, M., Underground coal gasification - the Velenje coal mine energy and economic calculations. Chem. Ind. Chem. Eng. Q, 2016, 42, 1-28.

55. Elahi, S. M., Geomechanical Modelling of Underground Coal Gasification, Thesis, University of Calgary, 2016.

56. Seddon, D., Lessons learned from underground coal gasification. Chem. Aust., 2016, 36-37.

57. Sajjad, M. and Rasul, M. G., Review on the existing and developing underground coal gasification techniques in abandoned coal seam gas blocks: Australia and global context. In Proceedings of the 1st International e-Conference on Energies, 2014, pp. 1-16.

58. Sharifi, M. and Young, B., Electrical resistance tomography applications to chemical engineering. Chem. Eng. Res. Des., 2013, 91, 1625-1645.

59. Mees, F., Swennen, R., Geet, M. V. and Jacobs, P., Applications of X-ray computed tomography in the geosciences. Geol. Soc. London, Spec. Publ., 2003, 215, 1-6.

60. Kumar, A., Jain, P. K. and Sharma, R. K., ONGC strive for underground coal gasification in India-past, present and future In Proceedings of Petrotech, 2010, 1-5.

61. Shackley, S., Mander, S. and Reiche, A., Public perceptions of underground coal gasification in the United Kingdom. Energy Policy, 2006, 34, 3423-3433.

62. Ministry of earth sciences, Gas hydrate in India-12th 5-year plan; http://dod.nic.in/programmes/gas-hydrates

63. Oil Industries Development Board, 1997; http://oidb.gov.in/ WriteReadData/LINKS/ce9e68f1-928e-4c13-87c2-5250caff0012. pdf

64. Delmo Group, Delmo group Carbon Energy UCG project key seam technology - Argentina, 2014; https://delmogroup.com/ claromeco-basin-ucg

65. North Eastern Coal Fields - About us, 2016; http://www neccoal.co.in/introduction.php

66. Exergy, E. Ergo Exergy - Abhijeet Group - UCG in India, 2015; http://www.ergoexergy.com/about us ourb projects ae.html

67. Bose, P. R., Essar Oil, Lanco, Adani bid for Coal India's underground gasification projects. Business Line, 2011.

68. Ministry of Coal, Steps for Development of Underground Coal Gasification Technology. PIB News Bulletin, 2015; http:// pib.nic.in/newsite/PrintRelease.aspx?relid=132935.

69. Vyas, D. U. and Singh, R. P., Worldwide developments in UCG and Indian initiative. Proc. Earth Planet. Sci., 2015, 11, 29-37.

ACKNOWLEDGEMENTS. One of the authors (A.S.) acknowledges financial support from CSIR in the form of Senior Research Fellowship. V.V.R. would like to acknowledge research funding from GAIL.

Received 15 September 2016; revised accepted 23 January 2017

doi: $10.18520 / \mathrm{cs} / \mathrm{v} 113 / \mathrm{i} 02 / 218-227$ 